\title{
EVALUACIÓN DE UNA PREMEZCLA ORGÁNICA COMERCIAL EN DIETAS DE CRECIMIENTO ENGORDE PARA CUYES (Cavia porcellus) SOBRE PARÁMETROS PRODUCTIVOS
}

\author{
EFFECT OF A COMMERCIAL FEED ADDITIVE ON THE PERFORMANCE OF GROWING \\ - FATTENING GUINEA PIGS (Cavia porcellus)
}

${ }^{1}$ Johan Portocarrero R. y ${ }^{2}$ Victor Hidalgo L.

\begin{abstract}
Resumen
El presente estudio se llevó a cabo en la Universidad Nacional Agraria La Molina entre noviembre 2012 y enero 2013. El objetivo fue investigar el efecto de una premezcla orgánica comercial (suplemento) en la dieta de cuyes (Cavia porcellus) en crecimiento-engorde sobre los parámetros productivos. Se utilizaron 96 cuyes machos de $19 \pm 2$ días de edad del genotipo Cieneguilla-UNALM, distribuidos al azar en tres tratamientos con ocho repeticiones cada uno bajo un Diseño Completamente al Azar. El estudio fue conducido durante un periodo de 49 días. Los tratamientos fueron: T1 (Dieta control), T2 (Dieta con $0.25 \%$ suplemento) y T3 (Dieta con $0.50 \%$ suplemento), los mismos que fueron evaluados durante 49 dias. El suplemento se mezcló con un alimento balanceado $(2.85 \mathrm{Mcal}$ energía digestible/Kg y $18.31 \%$ proteína cruda) y peletizado. Como forraje se suministró maíz chala al $10 \%$ del peso vivo. Los resultados no mostraron diferencias significativas $(\mathrm{P}>0.05)$ en los parámetros productivos (ganancia de peso, Consumo de materia seca, conversión alimenticia y rendimiento de carcasa) evaluados. Las dietas con suplemento nutricional (T2 y T3) tuvieron $5.56 \%$ y $11.59 \%$ más utilidad respectivamente en comparación a la dieta control (T1). Se concluye que el uso de la premezcla no afectó significativamente los parámetros productivos evaluados, observando solamente un mejor mérito económico con la inclusión del suplemento en la dieta de los cuyes.
\end{abstract}

Palabras claves: cuy, mérito económico, probiótico, parámetros productivos.

\begin{abstract}
This research was conducted at the National Agrarian University La Molina from November 2012 and January 2013. The effect of a nutritional commercial feed additive (supplement) in guinea pigs (Cavia porcellus) on the production parameters was evaluated in the growing-fattening phase. Ninety six male guinea pigs of $19 \pm 2$ days of age of the Cieneguilla-UNALM genotype, were randomly distributed into three treatments with eigth replicates each in a completely random design. The study was conducted during a 49 days period. The treatments were: T1 (Control group without any supplement), T2 (0.25\% supplement) and T3 (0.50\% supplement). The basal diet included a pelleted concentrate $(2.85 \mathrm{Mcal} \mathrm{DE} / \mathrm{kg}$ and $18.31 \%$ crude protein) and corn green forage ( $10 \%$ of live weight). There were no significant differences in the production parameters evaluated. The T2 and T3 treatments reported 5.56\% and $11.59 \%$ more margin over feed cost with respect to the control treatment. In conclusion, there were no significant differences in the production parameters evaluated; but a higher benefit/cost ratio of supplementation was found for supplementation.
\end{abstract}

Key words: guinea pig, merit, probiotic, performance.

\section{Introducción}

Como una estrategia para aumentar la producción de carne en granjas de cuyes comerciales, en los últimos años, se han venido usando promotores de crecimiento del tipo antibiótico, aditivos que son comúnmente usados en la producción avícola para el control de bacterias causantes de infecciones intestinales. Dentro del contexto ganadero, las enfermedades infecciosas cobran la vida de muchos animales, siendo los animales en crecimiento los más afectados, esto provoca pérdidas económicas importantes. Pero el abuso en el uso de antibióticos en la alimentación provoca incremento de la resistencia bacteriana, con un peligro latente de traspaso de esta resistencia a patógenos humanos. Ante esta situación, muchos Organismos Internacionales han prohibido el uso de algunos antibióticos en animales como medida de control; por cuanto se está optando en utilizar suplementos nutricionales para compensar los requerimientos y producción de anticuerpos necesarios para contrarrestar los agentes patógenos que conviven en las granjas de producción comercial principalmente. En los últimos años, se ha comenzado a buscar alternativas naturales de origen orgánico, como los probióticos y prebióticos, que puedan dar iguales o mejores resultados que con el uso de promotores de crecimiento. Al respecto, Ravindran (2010) define que los prebióticos son sustancias no digestibles que favorecen la colonización del tracto digestivo por bacterias beneficiosas. Para 
estimular el crecimiento de microorganismos deseables, los prebióticos deben ser usados por el microorganismo específico, tampoco deben ser digeridos por las enzimas del animal hospedero y deben alcanzar el intestino grueso para hacerse disponibles a los organismos probioticos. Para que estos últimos sean efectivos deben provenir de especies semejantes por lo tanto, se tendrá que producir probióticos a partir de la microbiota cuyo nicho ecológico sea el tracto digestivo de la especie animal (Porturas, 2011 cita a Rosmini, 2004).

Por otro lado, los Lactobacillus son bacterias probioticas más estudiadas por sus efectos positivos en la salud y crecimiento animal, así como por su capacidad de colonización y resistencia a enzimas y secreciones gastrointestinales que pudieran influir en sus efectos benéficos In vivo y ser una fuente de enzimas esenciales para el metabolismo de nutrientes (Rolfe, 2000). Al respecto, Mattos (2007), evaluó la inclusión de muña (Satureja parvifolia) como estimulador de Lactobacillus spp. y administró por siete días un probiótico comercial (Lactobacillus acidophillus y Lactobacillus bulgaricus) a cuyes de $14 \pm 2$ días de edad, seguida de una dosis infectiva de Salmonella typhimurium y reportó un peso vivo final y una ganancia total de peso de $628 \mathrm{~g}$ y $333 \mathrm{~g}$, respectivamente, a las seis semanas de evaluación. con un consumo de $1970 \mathrm{~g}$ de materia seca y una conversión alimenticia de 5.93 en el mismo periodo. Asimismo, Bourne (1991) al evaluar un probiótico comercial (Lactobacillus acidophillus, Streptococcus faecium y Saccharomyces cerevisiae) en cerdos en la fase de crecimiento-engorde, mejoró la ganancia diaria de peso y la eficiencia de conversión alimenticia en $8.26 \%$ y $5.0 \%$, respectivamente. Mientras que Soares (1999), citado por Paro (2009), no encontró diferencias significativas sobre los parámetros productivos en cerdos al evaluar la inclusión de enzimas fitasas y un complejo enzimático en dietas de recría crecimiento y acabado.

Al respecto, Revilla (2011) evaluó el efecto de la suplementación con minerales quelados en cuyes del genotipo Cieneguilla-UNALM en la fase de reproducción sobre los parámetros productivos, reportando pesos vivos promedio al nacimiento de $165.70 \mathrm{~g}$ y 174.5 , para niveles de solo $10 \%$ y $30 \%$ de suplementación mineral recomendada por el NRC (1995) respectivamente y $178.19 \mathrm{~g}$ para el tratamiento control; valores que no fueron estadística significativos $(\mathrm{P}>0.05)$. Asimismo este autor reportó diferencias estadísticas $(\mathrm{P}<0.05)$ en pesos al parto de las reproductoras de $1427.8 \mathrm{~g}$ y $1584.0 \mathrm{~g}$ para los niveles de $10 \%$ y $30 \%$ de suplementación mineral orgánica, respectivamente, según las recomendaciones del NRC (1995). Por otro lado, Jara (2013) evaluó tres niveles $(0.0,0.1$ y $0.2 \%)$ de un aditivo multifuncional comercial en la dieta de inicio $(0-35$ días) y de crecimiento (3663 días) de cuyes y no registró diferencias significativas en los parámetros productivos de las dos etapas de los cuyes. Este mismo autor, cita a Llamocuri (2012) quien evaluó la adición de Bio Mos y Rovabio Exel en dietas para inicio, crecimiento y acabado de cuyes, registrando valores promedios al final del estudio, en ganancia de peso $13.54 \mathrm{~g} /$ anima/día, consumo de materia seca 43.10 $\mathrm{g} /$ cuy/día, conversión alimenticia 3.54 y en rendimiento de carcasa $73.1 \%$.

El objetivo de esta investigación fue evaluar el efecto de un suplemento nutricional comercial en la dieta de cuyes en crecimiento - engorde, sobre los parámetros productivos como peso vivo final, ganancia de peso, consumo de alimento, conversión alimenticia, rendimiento de carcasa y el mérito económico.

\section{Materiales y métodos}

Se utilizaron 96 cuyes machos destetados de $19 \pm 2$ días de edad. Los cuales fueron aretados y distribuidos al azar en tres tratamientos con ocho repeticiones cada uno y cuatro cuyes por repetición, procedentes de la granja de cuyes de Cieneguilla del Programa de Investigación en Carnes. Como dieta basal se usó el alimento balanceado peletizado, preparado en la Planta de Alimento de la Universidad Nacional Agraria La Molina, y como forraje verde se utilizó maíz chala en una proporción de 10 por ciento del peso vivo promedio por poza. La composición porcentual de los ingredientes y composición nutricional se muestran en el Tabla 1. El suplemento nutricional comercial evaluado fue el Cobaplex, que es una premezcla usada en la alimentación de cuyes en sus diferentes etapas de viva. Su composición se detalla en el Tabla 2. Se evaluaron tres tratamientos: Tratamiento 1: Dieta control sin suplemento nutricional comercial. Tratamiento 2: Dieta con $0.25 \%$ de suplemento nutricional comercial y Tratamiento 3: Dieta con 0.50 $\%$ de suplemento nutricional comercial.

El medición del peso vivo se realizó una vez a la semana a las 8:00 a.m., se utilizó una balanza digital de $5 \mathrm{Kg}$ de capacidad y con $1.0 \mathrm{~g}$ de sensibilidad. En la noche anterior a la medición del peso vivo de los animales se retiró el alimento concentrado y el forraje. El alimento balanceado, previamente pesado, se suministró diariamente a las 8:00 a.m. utilizando un comedero tipo tolva. Igualmente se pesó el maíz chala y se suministró diariamente a las 8:30 am para ambas mediciones se utilizó una balanza digital de $5 \mathrm{Kg}$ de capacidad y con $1.0 \mathrm{~g}$ de sensibilidad. El agua fue ofrecida en bebederos de arcilla dos veces al día a las 8:00 a.m. y a las 4:00 p.m. El residuo del alimento balanceado se recogió y se pesó una vez por semana el mismo día y hora que se registró peso vivo de los animales. En cuanto a la recolección y pesado de residuos de maíz chala, se realizó diariamente a las 8:00 am.

\section{Mediciones de parámetros productivos Pesos y ganancias de peso}

Se calcularon las ganancias de peso de acuerdo a la siguiente fórmula:

Ganancia de peso $(\mathrm{g})=$ Peso vivo final $(\mathrm{g})-$ Peso vivo inicial $(\mathrm{g})$ 


\section{Consumo total de materia seca}

El consumo total de materia seca se calculó sumando el consumo total de materia seca proveniente tanto del alimento balanceado como del forraje registrados durante siete semanas de evaluación. Para calcular este parámetro se restó a la materia seca ofrecida menos la materia seca residual.

Tabla 1. Composición porcentual y valor nutritivo de las dietas y del maíz chala (base fresca).

\begin{tabular}{|c|c|c|c|c|}
\hline \multirow{2}{*}{ Componentes } & \multicolumn{3}{|c|}{ Tratamientos } & \multirow{2}{*}{$\begin{array}{l}\text { Maíz } \\
\text { chala }\end{array}$} \\
\hline & $\mathrm{T} 1$ & $\mathrm{~T} 2$ & T 3 & \\
\hline Subproducto de trigo & 57.89 & 57.64 & 57.4 & \\
\hline Hominy feed & 17.98 & 17.98 & 17.98 & \\
\hline Gluten de maíz & 11.99 & 11.99 & 11.99 & \\
\hline Torta de soya & 7.49 & 7.49 & 7.49 & \\
\hline Harina de alfalfa & 3 & 3 & 3 & \\
\hline Carbonato de calcio & 1 & 1 & 1 & \\
\hline Fosfato dicalcico & 0.2 & 0.2 & 0.2 & \\
\hline Metionina & 0.05 & 0.05 & 0.05 & \\
\hline Sal común & 0.3 & 0.3 & 0.3 & \\
\hline Cobaplex ${ }^{1}$ & $\mathbf{0}$ & 0.25 & 0.5 & \\
\hline Rovimix Stay - C $35 \circledR^{2}$ & 0.1 & 0.1 & 0.1 & \\
\hline Total & 100 & 100 & 100 & \\
\hline \multicolumn{5}{|l|}{ Composición nutricional ${ }^{3}$} \\
\hline Materia seca, $\%$ & 87.61 & 87.6 & 87.89 & 33.51 \\
\hline Proteína total, \% ( $\mathrm{N} \times 6.25)$ & 18.35 & 18.21 & 18.37 & 2.39 \\
\hline Extracto etéreo, \% & 4.87 & 4.82 & 4.8 & 0.52 \\
\hline Fibra cruda, $\%$ & 6.77 & 6.73 & 6.96 & 8.31 \\
\hline Ceniza, \% & 5.71 & 5.74 & 5.7 & 1.52 \\
\hline $\begin{array}{l}\text { Extracto libre de nitrógeno, } \\
\%\end{array}$ & 51.91 & 52.1 & 52.06 & 20.77 \\
\hline
\end{tabular}

\section{Conversión alimenticia}

Se calculó a partir del consumo total de materia seca y la ganancia total de peso vivo, según la siguiente fórmula:

$$
\text { Conversión alimenticia acumulada }=\frac{\text { Consumo total de materia seca }(\mathrm{g})}{\text { Ganancia total depeso vivo }(\mathrm{g})}
$$

\begin{tabular}{|c|c|c|}
\hline Componente & Unidad & Contenido \\
\hline Saccharomyces $\mathrm{sp}$ & UFC & $5 \times 10^{10}$ \\
\hline Lactobacillus & UFC & $2 \times 10^{9}$ \\
\hline Enzimas & $\mathrm{mg}$ & 2.20 \\
\hline Glucanos y mananos & $\%$ & 1.50 \\
\hline Vitamina A & UI & 5000000 \\
\hline Vitamina D3 & UI & 325000 \\
\hline Vitamina E & UI & 10000 \\
\hline Vitamina $\mathrm{C}$ & $\mathrm{g}$ & 40.00 \\
\hline Ácido aspárgico & $\mathrm{mg}$ & 540.00 \\
\hline Ácido glutámico & $\mathrm{mg}$ & 315.00 \\
\hline Alanina & $\mathrm{mg}$ & 280.00 \\
\hline Arginina & $\mathrm{mg}$ & 105.40 \\
\hline Fenilalanina & $\mathrm{mg}$ & 100.40 \\
\hline Glicina & $\mathrm{mg}$ & 44.20 \\
\hline Histidina & $\mathrm{mg}$ & 71.20 \\
\hline Isoleucina & $\mathrm{mg}$ & 59.40 \\
\hline Leucina & $\mathrm{mg}$ & 73.60 \\
\hline Lisina & $\mathrm{mg}$ & 811.80 \\
\hline Metionina & $\mathrm{mg}$ & 1500.00 \\
\hline Prolina & $\mathrm{mg}$ & 650.00 \\
\hline Serina & $\mathrm{mg}$ & 80.00 \\
\hline Tirosina & $\mathrm{mg}$ & 500.00 \\
\hline Treonina & $\mathrm{mg}$ & 200.00 \\
\hline Triptofano & $\mathrm{mg}$ & 20.00 \\
\hline Valina & $\mathrm{mg}$ & 60.00 \\
\hline Ácidos orgánicos & $\%$ & 12.00 \\
\hline Quelato de cobalto & $\mathrm{mg}$ & 10.00 \\
\hline Quelato de cobre & $\mathrm{g}$ & 10.00 \\
\hline Quelato de hierro & $\mathrm{g}$ & 2.50 \\
\hline Quelato de magnesio & $\%$ & 1.00 \\
\hline Quelato de manganeso & $\mathrm{g}$ & 12.00 \\
\hline Quelato de zinc & $\mathrm{g}$ & 30.00 \\
\hline Quelato de selenio & $\mathrm{mg}$ & 25.00 \\
\hline
\end{tabular}

Tabla 2. Composición de la premezcla orgánica comercial.

Fuente: Laboratorios PROVET S.A.C.

\section{Rendimiento al Beneficio}

Todos los animales fueron beneficiados a las 7 semanas de evaluación previo ayuno de 24 horas. Se registraron los valores de peso vivo al beneficio, peso de carcasa y el rendimiento de carcasa; este último se calculó utilizando la siguiente fórmula:

$$
\begin{aligned}
& \text { Rendimiento de carcasa }=\frac{\text { Peso de carcasa }(\mathrm{g})}{\text { Peso vivo al beneficio }(\mathrm{g})} \times 100 \\
& \text { Mérito económico }(\%)=\frac{\mathrm{UB} \text { por } \mathrm{Kg} \text { peso vivo } / \text { Tratamiento }}{\mathrm{UB} \text { por } \mathrm{Kg} \text { peso vivo } / \text { Contraste }} \times 100 \\
& \text { UB por cuy/ tratamiento }=\mathrm{IT} \text { por cuy }-\mathrm{CTP} \text { por cuy } \\
& \text { UB por Kg peso vivo }=\mathrm{Utilidad} \text { bruta por Kg peso vivo } \\
& (\mathrm{S} / .) \\
& \text { UB por cuy }=\text { Utilidad bruta por cuy }(\mathrm{S} / .) \\
& \text { IT por cuy }=\text { Ingreso total por cuy }(\mathrm{S} / .) \\
& \text { CTP por cuy }=\text { Costo total de producción por cuy }(\mathrm{S} / .)
\end{aligned}
$$


Los promedios del efecto de los tratamientos fueron analizados mediante el Diseño Completamente al Azar, con tres tratamientos y ocho repeticiones por tratamiento y se realizó el análisis de varianza (ANVA) para los parámetros productivos. Los datos fueron procesados con el programa estadístico SAS versión 8.0. Para la comparación de medias se realizó la prueba de Duncan para determinar las diferencias estadísticas o no entre tratamientos con un nivel de significación de 5\% (Calzada, 1982).

\section{Resultados y Discusión}

Los promedios de peso vivo final y ganancia total de peso vivo por tratamiento se muestran en la Tabla 3. Los resultados de ambos parámetros no mostraron diferencias estadísticas

$(\mathrm{P}>0.05)$ por efecto de los tratamientos. Los valores de peso vivo final para T1 (control), T2 $(0.25 \%)$ y T3 $(0.50 \%)$ fueron de $1065.60,1080.78$ y $1102.53 \mathrm{~g}$; la ganancia total de peso a las siete semanas de evaluación (10 semanas de edad), fueron $776.78 \mathrm{~g}, 794.97 \mathrm{~g}, \mathrm{y}$ $818.70 \mathrm{~g}$, respectivamente.

Tabla 3. Parámetros productivos registrados por tratamiento ${ }^{1}$.

\begin{tabular}{|c|c|c|c|}
\hline \multirow{2}{*}{ Parámetros } & \multicolumn{3}{|c|}{ Tratamientos } \\
\hline & $\mathrm{T} 1$ & $\mathrm{~T} 2$ & T3 \\
\hline $\begin{array}{l}\text { Peso vivo inicial } \\
\text { (g) }\end{array}$ & $289 \pm 7.3^{a}$ & $286 \pm 6.6^{\mathrm{a}}$ & $284 \pm 7.3^{a}$ \\
\hline $\begin{array}{l}\text { Peso vivo final } \\
\text { (g) }\end{array}$ & $\begin{array}{l}1066 \pm \\
69.6^{a}\end{array}$ & $1081 \pm 49.0^{a}$ & $1103 \pm 45.5^{\mathrm{a}}$ \\
\hline $\begin{array}{l}\text { Ganancia total de } \\
\text { peso }(\mathrm{g})\end{array}$ & $\begin{array}{l}777 \pm \\
70.2^{a}\end{array}$ & $795 \pm 51.1^{a}$ & $819 \pm 43.3^{\mathrm{a}}$ \\
\hline $\begin{array}{l}\text { Consumo total } \\
\text { de materia seca } \\
\text { (g) }\end{array}$ & $\begin{array}{c}2410 \pm \\
28.1^{\mathrm{a}}\end{array}$ & $2399 \pm 21.0^{a}$ & $2425 \pm 17.2^{a}$ \\
\hline $\begin{array}{l}\text { Conversión } \\
\text { alimenticia } \\
\text { acumulada }\end{array}$ & $3.1 \pm 0.25^{\mathrm{a}}$ & $3.0 \pm 0.17^{\mathrm{a}}$ & $2.96 \pm 0.15^{\mathrm{a}}$ \\
\hline $\begin{array}{l}\text { Rendimiento al } \\
\text { beneficio }(\%)\end{array}$ & $74.2 \pm 1.4^{\mathrm{a}}$ & $74.4 \pm 1.8^{a}$ & $75.6 \pm 1.80^{a}$ \\
\hline
\end{tabular}

${ }^{1}$ Correspondiente a siete semanas de evaluación (10 semanas de edad). ${ }^{a}$ Letras iguales indican similitud estadística $(\mathrm{P}>0.05)$.

Los valores registrados, concuerdan con los resultados reportados por Jara (2013) quien tampoco observó diferencias significativas en los mismos parámetros producticos, por efecto de tres niveles $(0.0,0.1$ y 0.2 $\%$ ) de un aditivo multifuncional en dietas de cuyes de inicio ( 0 - 35 días) y de crecimiento ( $36-63$ días). Pero, comparando los resultados de este estudio con los de Mattos (2007), no concuerdan por que este autor registró diferencias significativas en peso vivo final y ganancia total de peso al suministrar por siete días un probiótico comercial (Lactobacillus acidophillus y Lactobacillus bulgaricus) con inclusión de muña (Satureja parvifolia) como estimulador de Lactobacillus spp. a cuyes de $14 \pm 2$ días de edad, seguida de una dosis infectiva de Salmonella typhimurium. Este mismo autor en el año 2003 investigó el uso de ensilado de pescado que contenían bacterias lácticas del yogurt, en la alimentación de cuyes mejorados destetados de $14 \pm 3$ días de edad del genotipo Perú; registrando mejoras significativas $(\mathrm{P}<0.05)$ respecto al tratamiento control (T0). Atribuyendo este resultado, entre otros factores, al efecto benéfico de dichas bacterias lácticas sobre la flora gastrointestinal de los cuyes.

Investigaciones en otras especies como la realizada por Arroyo (2003), muestra el efecto de un cultivo comercial liofilizado (Lactobacillus acidophillus, Lactobacillus plantarum y Bacillus subtilis) en la alimentación de conejos, reportando una ganancia total de peso de $1125.65 \mathrm{~g}$ con el tratamiento de $0.1 \%$ de inclusión de cultivo comercial, superando al tratamiento testigo ( $\sin$ aditivo) que ganaron $1019.83 \mathrm{~g}$. Por otra parte Bourne (1991), al evaluar un probiótico comercial (Lactobacillus acidophillus, Streptococcus faecium y Saccharomyces cerevisiae) en cerdos en la fase de crecimiento-engorde, reportó mejoras en la ganancia diaria de peso en $8.26 \%$ respecto al testigo. Los resultados no significativos obtenidos en el presente estudio pueden atribuirse al tipo de cepa de los organismos probióticos de la premezcla comercial evaluada que no correspondía a la especie animal, como manifiestan Donald (2000), Rosmini (2004), citados por Porturas (2011), que un organismo probiótico para ser efectivo debe provenir de especies semejantes y utilizarse en el mismo lugar donde debe actuar en el huésped.

Los promedios del consumo total de materia seca y de conversión alimenticia acumulada por tratamiento se muestran en la Tabla 3. Los valores de consumo total de materia seca (Concentrado y forraje) indican que no existen diferencias estadísticas $(\mathrm{P}>0.05)$ a las siete semanas de evaluación por efecto del tratamiento. En otros estudios observaron diferencias estadísticas como el reportado por De Ondarzá y Silvano-Jones (2000) quienes afirman que los animales tratados con estimulantes de la flora bacteriana presentan un mejor balance bacterial del tracto digestivo y por ende una mejor performance. Asimismo, Mattos (2007) al evaluar la inclusión de muña (Satureja parvifolia) en la dieta como estimulador de Lactobacillus spp., por siete días y un probiótico comercial (Lactobacillus acidophillus y Lactobacillus bulgaricus) a cuyes de $14 \pm 2$ días de edad, seguida de una dosis infectiva de Salmonella typhimurium, reportó diferencias significativas en los consumos de materia seca para los tratamientos con $2 \%$ y $4 \%$ de inclusión de muña, reportando valores de 1335 g y $1250 \mathrm{~g}$, respectivamente, comparados con el tratamiento testigo que registró un consumo de $1970 \mathrm{~g}$ de materia seca.

Es importante señalar que la mayoría de los experimentos que utilizaron nutrientes y sustancias que contiene este suplemento comercial han sido evaluados en especies distintas al cuy, con diferencias en comportamiento 
alimenticio, sistema digestivo y metabolismo, probablemente sean una limitante para obtener los resultados esperados. Además, la mayoría de los estudios con aditivos alimentarios fueron llevados a cabo en condiciones controladas (laboratorios o granjas experimentales), al igual que el presente ensayo, lo que podría explicar la no obtención de los efectos benéficos de las sustancias orgánicas adicionadas en las dietas. Al respecto, algunos investigadores sugieren que sustancias orgánicas como probióticos y prebióticos, e incluso promotores de crecimiento del tipo antibiótico, logran mejores resultados cuando las condiciones de crianza presentan algunos problemas sanitarios, nutricionales o de manejo ( Rolfe, 2000).

Asimismo, en la Tabla 3 se muestran los promedios de conversión alimenticia acumulada. Los mismos que no mostraron diferencias significativas por efecto del tratamiento a las siete semanas de evaluación. Estos promedios indican que no hubo una mejora en la absorción de nutrientes por efecto de los tratamientos. Esto no concuerda con lo reportado por Mattos (2007), que evaluó la inclusión de muña como estimulador de desarrollo de Lactobacillus spp., después de siete días de suplemento de un probiótico comercial a cuyes de $14 \pm 2$ días de edad, seguida de una dosis infectiva de Salmonella typhimurium, reportando diferencias significativas en la conversión alimenticia por efecto de la muña.

Los valores obtenidos, además de la probable especificidad de los probióticos en el tipo de tracto y flora digestiva de una especie animal, pueden relacionarse con el efecto de la temperatura en el proceso de peletizado, el cual pudo haber afectado la integridad de algunos microorganismos reduciendo su actividad; de manera similar podría haber sucedido con la actividad de las enzimas por efecto del calor (Paro, 2009 cita a Soares, 1999). Si bien los componentes como enzimas y ácidos orgánicos contenidos en el suplemento ayudarían a mejorar la digestibilidad y utilización en especies monogástricos como pollos y porcinos, como afirma Ravindran (2010), recomendando realizar estudios para conocer si es viable el uso de enzimas y otros compuestos similares en dietas de especies herbívoros capaces de digerir estructuras vegetales del alimento balanceado y por supuesto del forraje.

En la Tabla 3 se muestran los promedios de rendimiento al beneficio por tratamiento. Estos valores no mostraron diferencias estadísticas ( $\mathrm{P}>0.05)$, como en otros estudios con el mismo genotipo y condiciones de crianza; si bien no hubo diferencias significativas pero se obtuvo una ventaja numérica en cuanto al peso de carcasa en los tratamientos con inclusión de suplemento nutricional comercial.

En cuanto al mérito económico y el ingreso bruta por kilogramo de peso vivo por tratamiento

se pueden apreciar en la Tabla 4. Los mayores porcentajes en el mérito económico con respecto al tratamiento testigo (T1), indican una mejor respuesta económica.
Tabla 4. Efecto de los tratamientos sobre el mérito económico. ${ }^{1}$

\begin{tabular}{|c|c|c|c|}
\hline Parámetros & $\mathrm{T} 1$ & $\mathrm{~T} 2$ & $\mathrm{~T} 3$ \\
\hline Costo de producción (S/./cuy) & 14.65 & 14.67 & 14.75 \\
\hline Animales & 12 & 12 & 12 \\
\hline Alimentación 2,3 & 2.65 & 2.67 & 2.75 \\
\hline Ingreso total (S/./cuy) & 18.11 & 18.37 & 18.74 \\
\hline Precio de venta (S/./Kg PV) & 17 & 17 & 17 \\
\hline Peso vivo final (Kg/cuy) & 1.07 & 1.08 & 1.1 \\
\hline Utilidad bruta (S/./cuy) & 3.46 & 3.71 & 4 \\
\hline Utilidad bruta $(\mathrm{S} / . / \mathrm{kg})$ & 3.23 & 3.43 & 3.64 \\
\hline Mérito económico $(\%)$ & 100 & 105.56 & 111.59 \\
\hline
\end{tabular}

${ }^{\mathrm{1}}$ Correspondiente a siete semanas de evaluación (10 semanas de edad).

${ }^{2}$ Los precios del alimento balanceado fueron de S/. 1.48/ Kg MS (T1),

$\mathrm{S} / .1 .51 / \mathrm{Kg} \quad \mathrm{MS}(\mathrm{T} 2)$ y S/ $1.53 / \mathrm{Kg}$ MS (T3).

${ }^{3}$ El precio del forraje maíz chala fue de S/. 0.57/Kg MS.

Al respecto, el tratamiento T2 dio S/.0.18 más utilidad que el tratamiento $\mathrm{T} 1$ (control), que en términos porcentuales equivale a $5.56 \%$ más utilidad. Asimismo con el tratamiento T3 $(0.50 \%$ de suplemento $)$ se registró $\mathrm{S} / .0 .38$ más utilidad con respecto al control (T1), que equivale en promedio a $11.59 \%$ más utilidad. Esta ventaja numérica en el peso vivo final podría significar un importante margen de utilidad en granjas tecnificadas donde se manejan grandes volúmenes de ventas de cuyes.

En conclusión, el uso del suplemento nutricional comercial en el alimento balanceado no afectó significativamente ningún parámetro productivo al término del estudio experimental. Sin embargo, los tratamientos con suplemento nutricional comercial mostraron un mayor mérito económico con respecto al tratamiento control.

\section{Literatira citada}

Arroyo, D.2003. Probióticos en Conejos. Trabajo monográfico. Universidad Nacional Agraria La Molina. Lima, Perú.

Bourne, S. 1991. Lacto-Sacc vs Avotan: Comparative effects on Growing pigs. Newsman Hybrid Pig, Great Britain. Biotechnology in the feed Industry. Proceeding of Alltech's Seventh Annual Symposium. Edit by T.P. Lyons. Nicholasville, Kentuchy 40356. 395 p.

Calzada B., J. 1982. Métodos Estadísticos para la investigación. Universidad Nacional Agraria La Molina. Lima. Perú.

De Ondarzá, M. Y Silvano-Jones, J. 2000. Intake and milk production of dairy cows fed lactic acid bacteria and mannanoligosaccharides. Report by F.A.R.M.E. Institute; Homer, New York, USA.

Jara, N. N. L. 2013. Evaluación de un aditivo multifunctional en la dieta sobre el comportamiento productivo de cuyes (Cavia porcellus) en crecimiento. Tesis. Universidad Nacional Agraria La Molina. Lima, Perú. 
Mattos, J. 2003. uso del ensilado biológico de pescado en la alimentación de cuyes mejorados. Revista Inv. de Veterinaria del Perú 2003; 14(2): 89-96

Mattos, J. 2007. Efecto de la Muña (Satureja parvifolia) como aditivo no nutricional en la estimulación de Lactobacillus spp. U control de Salmonella thyphimurium en cuyes de carne. Tesis. Universidad Nacional Agraria La Molina. Lima, Perú.

National Research Council (NRC). 1995. Nutrient Requeriments of Laboratory Animals. Fourth Revised Edition.Washington. USA. 192 p.

Paro, M. J. 2009. Enzimas en el alimento de cerdos desde la fese de recría hasta el acabado. Trabajo monográfico. UNALM. Lima, Perú

Porturas, A. K. 2011. Aislamiento e identificación por técnicas moleculares de aislados bacterianos pertenecientes a géneros con potencial aplicación probiótico presentes en el intestino delgado de cuyes (Cavia porcellus). Tesis Med. Veterinario, UNMSM. Perú

Ravindran, V. 2010. XXVI Curso de Especialización FEDNA. Aditivos en alimentación animal: Presente y futuro. Institute of Food, Nutrition and Human Health, Massey University, Palmerston North 4442, New Zealand. 24 p. Disponible en: http://fundacionfedna.org/ sites/default/files/10CAP_I.pdf.

Revilla, J. 2011. Evaluación de la performance de cuyes (Cavia porcellus) suplementados con minerales orgánicos quelados en la fase de reproducción. Tesis. Universidad Nacional Agraria La Molina. Lima, Perú.

Rolfe, R. 2000. The Role of Probiotic Cultures in the Control of Gastrointestinal Health. En Symposium: Probiotics Bacteria: Implications for Human Health. J. Nutr. 130: 396-402. 